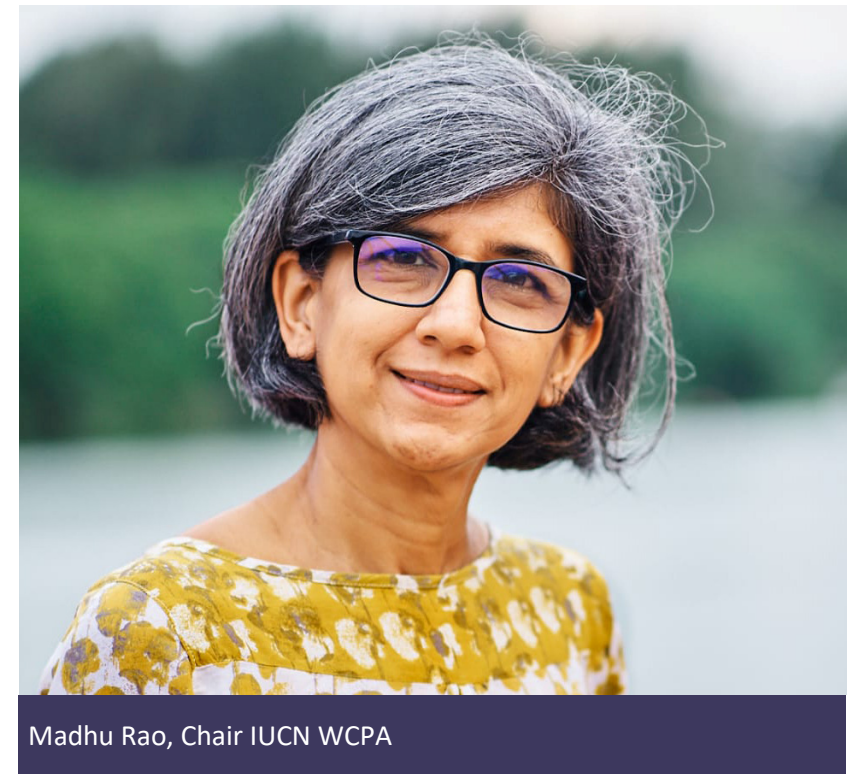

\section{EDITORIAL FROM THE WCPA CHAIR AND DEPUTY CHAIR Positioning for impact at scale: WCPA priorities for stewardship of nature to 2030 and beyond}

Safeguarding natural ecosystems from further degradation and collapse is an existential challenge for humanity. Equitable, well managed and effective networks of protected and conserved areas (PCAs) should form the core of our response to the current biodiversity and climate crises. The World Commission on Protected Areas (WCPA) is uniquely positioned as a provider of technical support to relevant actors to effectively secure natural ecosystems for biodiversity and human well-being.

The core mission of the WCPA is to develop and provide scientific, technical and policy advice and to advocate for global and national systems of marine, freshwater and terrestrial protected areas and other effective areabased conservation measures (OECMs) that result in successful outcomes for the conservation of biodiversity, based on principles of sound design, good management and equitable governance.

The core value of the Commission lies within its themes, specialist groups, and task forces that define its technical strengths and unique contribution to functioning systems of protected and conserved areas. They drive innovation through rigorous technical guidance and practical tools to achieve well-functioning global systems of protection through engagement with

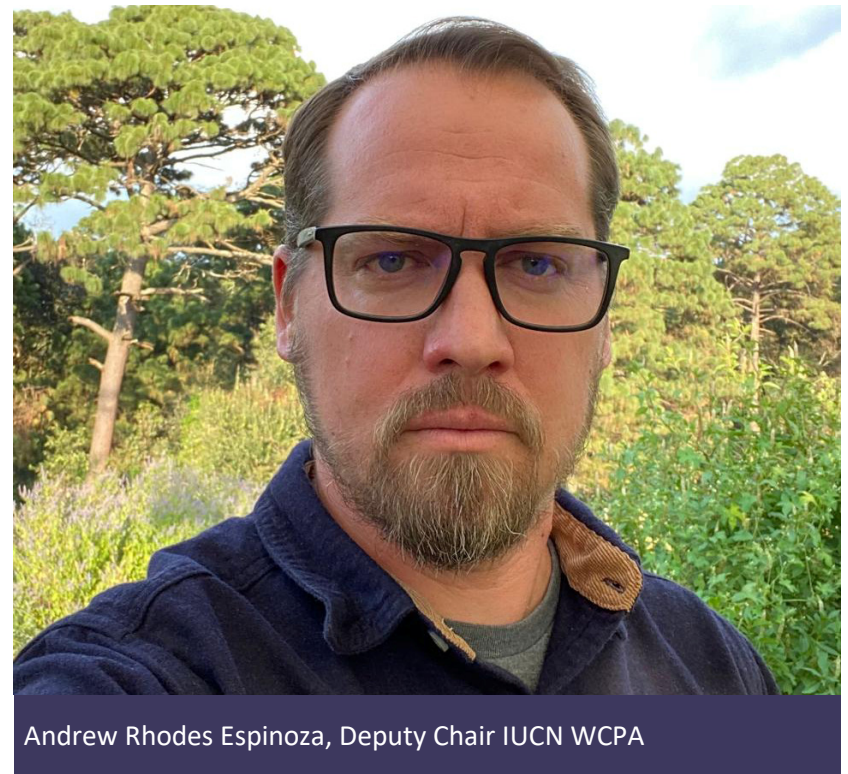

diverse constituencies. The strong regional networks of WCPA ensure that this work in developing guidance for PCAs is grounded in an understanding of the diverse circumstances that apply around the world.

We begin the new quadrennium with PCAs facing intense and complex challenges. Economic forces linked to the escalating demand for natural resources are creating enormous pressures on PCAs. Within this context of intensifying threat, our responsibility as a Commission is to ensure that systems of PCAs can not only hold their ground but also expand in spatial scale (quantity) and effectiveness (quality) to protect the ecosystems needed for a healthy planetary future.

Looking into the decade ahead as it unfolds, priorities for the Commission build on its core technical strengths, and positioning within the Union, as a key global knowledge-broker and standard-setter for protected areas.

The IUCN World Conservation Congress 2021 manifesto implored governments to set ambitious targets for protected areas and OECMs, calling for at least 30 per cent of the planet to be protected by 2030. Further, it noted that these targets must be based upon the latest science and reinforce rights - including Free Prior and Informed Consent - as set out in the UN Declaration on the Rights of Indigenous Peoples.

In alignment with the IUCN Programme and the Marseille Manifesto, WCPA will build its work with a foundational emphasis on conservation outcomes. Ensuring that existing and new PCAs are effective in 


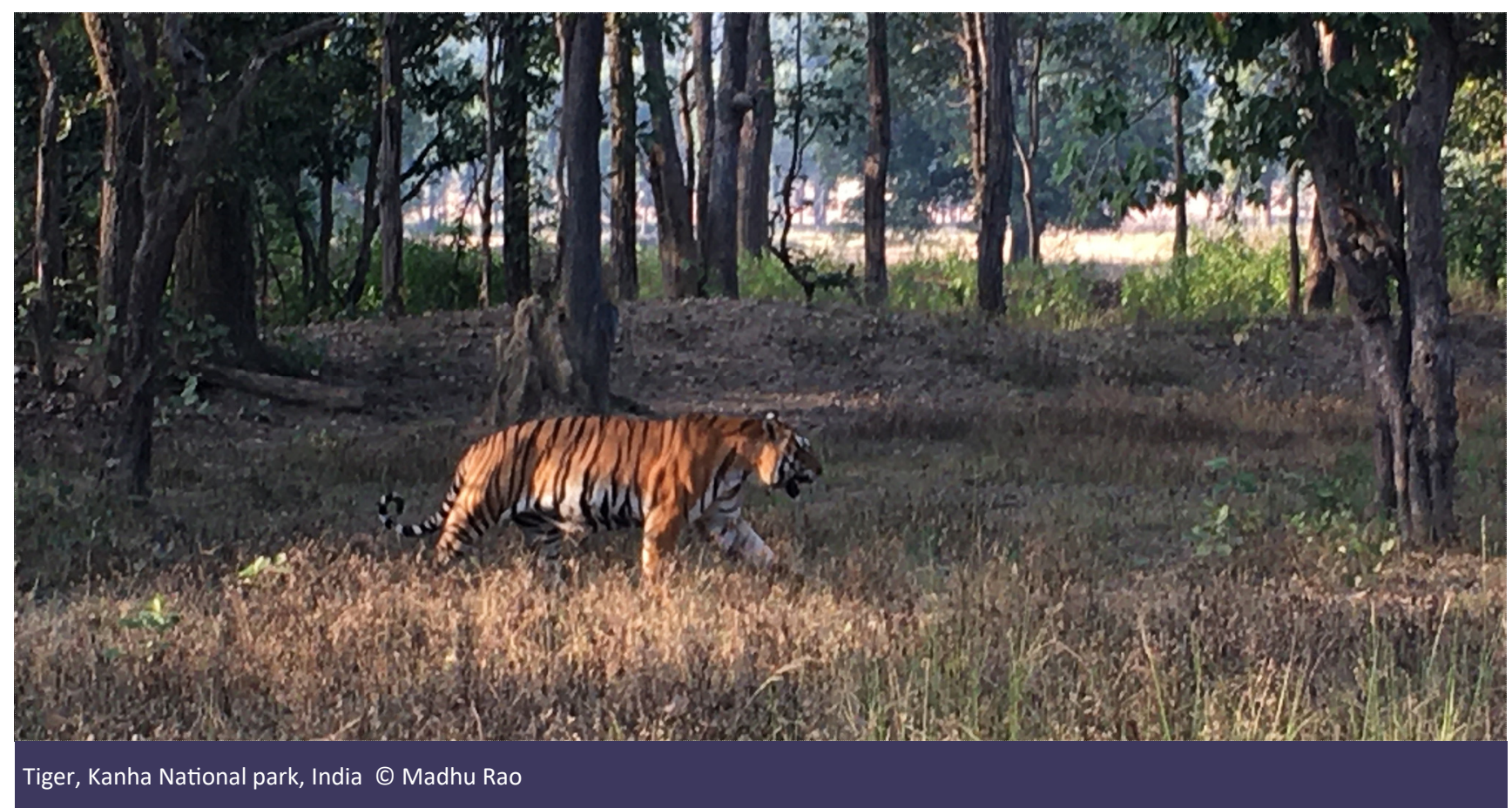

achieving biodiversity outcomes - with due respect for and recognition of the rights of people dependent on the area and its resources. Protected and conserved areas are intended to deliver positive benefits for nature, and especially for biodiversity conservation.

This is a fundamental shift, building on good intentions for conservation but moving to demonstrable, sustainable results. The placement of conservation outcomes for PCAs in the front and at the centre of its mission will define the Commission's work in the coming decade.

Achieving effective conservation outcomes requires that protected and conserved areas are equitably governed and effectively managed. WCPA can contribute significantly towards improving effectiveness of areabased conservation measures in many ways, including through supporting the implementation of the IUCN Green List Standard; supporting PCAs to measure, improve and maintain their performance; through to promoting globally consistent criteria that benchmark good governance, sound design and planning, and effective management.

The following are six key priorities of the WCPA as we head into the next quadrennium:

Supporting implementation of Post 2020 Global Biodiversity Framework Target 3 (30x30)

Area-based conservation through the establishment and management of "protected and conserved" areas lies at the heart of the Global Biodiversity Framework being negotiated by the Parties to the Convention on Biological Diversity (CBD). Achieving Target 3 (30 per cent of land and sea in effective, equitable, ecologically representative and well-connected protected and conserved areas by 2030) will require an unprecedented effort to establish, restore and effectively manage a global network of protected and conserved areas (PCAs). WCPA has played an important role in the development of relevant technical guidance including but not restricted to Key Biodiversity Areas, Important Marine Mammal Areas and connectivity. WCPA, with its 3,000 technical experts in 160 countries, has a unique role to play in providing essential technical and scientific support to government agencies, civil society organisations, intergovernmental organisations, NGOs, Indigenous Peoples' organisations and communities and private actors for successful implementation of Target 3 .

\section{Protecting and restoring priority ecosystems for biodiversity value, ecosystem services and carbon retention}

The WCPA will support and help implement, in priority countries, broad-scale spatial planning to actively identify opportunities for PCAs where there are significant biodiversity values, ecosystem services and carbon retention for protection and restoration. Based on WCPA's work on natural solutions, this will bring capacity for decision-makers and stakeholders on best practices in relation to key science, planning processes and decision-support tools. Improving the protection of the last remaining intact forests and wilderness areas, 
along with freshwater, mangrove and peatland ecosystems, for example, can help achieve both biodiversity and climate mitigation goals.

\section{Diversification of governance and management models}

Filling gaps in protected and conserved areas coverage will require a wide range of governance and management models through liaising with a range of government and non-government actors. WCPA can promote implementation of OECMs, privately protected areas and urban protected areas by supporting the integration of these measures into national accounting mechanisms.

\section{Strengthening financial capacity for PCAs}

Institutions managing PCAs need to have long-term adequate financing and to leverage diverse finance tools to achieve desired biodiversity outcomes and management objectives - the goal of sustainable finance. Historically, area-based conservation remains under-resourced, often overly reliant on a single income source such as donor-funding, tourism or government budgets. The development of new, innovative and resilient sources of finance is critical if area-based conservation mechanisms are to reach their full potential.

WCPA through its newly reorganised Sustainable Finance Specialist Group will enable and empower areabased conservation actors by developing and sharing knowledge, building awareness and capacity, and promoting strategic innovation in sustainable finance solutions.

\section{Capacity development and professionalisation}

Increased ambition for the global coverage of PCAs has massive implications for human capital. Achieving conservation outcomes for existing and new areas requires a major scaling up of the numbers and diversity of people directly involved in area-based management, extending beyond the 'conventional' management models. Objectives of the Capacity theme will include providing new and existing personnel and stewards with the required recognition, qualifications, skills and resources for effective and equitable management. This will involve both advancing the further professionalisation of 'conventional' protected area personnel (including rangers) and understanding and addressing the capacity needs and contributions of Indigenous and community stewards of existing and future protected areas and OECMs.

\section{Scaling up}

Ambitious global commitments for biodiversity (e.g. 30x30) and climate (1.5 degrees) require a radical rethink and shift in approach: in theory WCPA could be providing technical support to a third of the planet's surface. Consequently, an urgent need is to scale up our impact, building on the expert-driven volunteer system of WCPA that has served well until now. This includes but is not limited to guiding the design and management of PCAs as natural solutions to global challenges such as climate change, land degradation, food and water security, health and well-being. We need to purposefully integrate PCAs into the global climate, human health and restoration agendas, always maintaining a focus on the core biodiversity mandate for PCAs. An important priority for WCPA will be to inspire a new generation of conservation leaders and young professionals, across geographies and cultures, to engage with the work of the Commission.

The loss of nature is widely acknowledged as a risk to global societies. Protecting nature is not just an economic imperative, it is essential for human wellbeing, including prevention of future pandemics within a climate change context. WCPA can contribute impact at scale by building on its core strength as the technical backbone for the global system of protected and conserved areas. 